\title{
Article \\ Antifungal and Anti-Biofilm Effects of Caffeic Acid Phenethyl Ester on Different Candida Species
}

\author{
Ibrahim Alfarrayeh ${ }^{1,2}, * \mathbb{1}$, Edit Pollák ${ }^{3}$, Árpád Czéh ${ }^{4}$, András Vida ${ }^{4}$, Sourav Das ${ }^{5}$ (i) and Gábor Papp ${ }^{1}$ \\ 1 Department of General and Environmental Microbiology, Faculty of Science, University of Pécs, Ifjúság Str. 6, \\ 7624 Pécs, Hungary; pappgab@gamma.ttk.pte.hu \\ 2 Department of Biological Sciences, Faculty of Science, Mu'tah University, Mu'tah University Street, \\ Al-Karak 61710, Jordan \\ 3 Department of Animal Anatomy and Developmental Biology, Faculty of Science, University of Pécs, \\ Ifjúság Str. 6, 7624 Pécs, Hungary; peditmail@gmail.com \\ 4 Soft Flow Hungary R\&D Ltd., Ürögi Fasor Str. 2/ A, 7634 Pécs, Hungary; aczeh@foss.dk (Á.C.); \\ avida@foss.dk (A.V.) \\ 5 Department of Laboratory Medicine, Medical School, University of Pécs, Ifjúság Str. 13, 7624 Pécs, Hungary; \\ pharma.souravdas@gmail.com \\ * Correspondence: alfarrayeh@gmail.com; Tel.: +962-790-632-435
}

Citation: Alfarrayeh, I.; Pollák, E.; Czéh, Á.; Vida, A.; Das, S.; Papp, G. Antifungal and Anti-Biofilm Effects of Caffeic Acid Phenethyl Ester on Different Candida Species. Antibiotics 2021, 10, 1359. https://doi.org/ 10.3390/antibiotics10111359

Academic Editors: Luís Melo and Andreia S. Azevedo

Received: 30 September 2021

Accepted: 3 November 2021

Published: 7 November 2021

Publisher's Note: MDPI stays neutral with regard to jurisdictional claims in published maps and institutional affiliations.

Copyright: (c) 2021 by the authors. Licensee MDPI, Basel, Switzerland. This article is an open access article distributed under the terms and conditions of the Creative Commons Attribution (CC BY) license (https:// creativecommons.org/licenses/by/ $4.0 /)$.
Abstract: This study investigated the effect of CAPE on planktonic growth, biofilm-forming abilities, mature biofilms, and cell death of C. albicans, C. tropicalis, C. glabrata, and C. parapsilosis strains. Our results showed a strain- and dose-dependent effect of CAPE on Candida, and the MIC values were between 12.5 and $100 \mu \mathrm{g} / \mathrm{mL}$. Similarly, the MBIC values of CAPE ranging between 50 and $100 \mu \mathrm{g} / \mathrm{mL}$ highlighted the inhibition of the biofilm-forming abilities in a dose-dependent manner, as well. However, CAPE showed a weak to moderate biofilm eradication ability (19-49\%) on different Candida strains mature biofilms. Both caspase-dependent and caspase-independent apoptosis after CAPE treatment were observed in certain tested Candida strains. Our study has displayed typical apoptotic hallmarks of CAPE-induced chromatin margination, nuclear blebs, nuclear condensation, plasma membrane detachment, enlarged lysosomes, cytoplasm fragmentation, cell wall distortion, whole-cell shrinkage, and necrosis. In conclusion, CAPE has a concentration and strain-dependent inhibitory activity on viability, biofilm formation ability, and cell death response in the different Candida species.

Keywords: CAPE; Candida; antifungal; biofilm; apoptosis

\section{Introduction}

The genus Candida refers to a yeast that is part of the microbiota of healthy individuals living in commensalism with the human. However, in some cases, few Candida species tend to be opportunistic fungal pathogens, causing candidiasis. Candidiasis is among the common human infections; its symptoms vary according to the location of the infection in the body. Most of the infections may lead to minor symptoms such as slight localized rashes, redness, itching, and discomfort, though symptoms can be severe or even fatal if left without treatment in immunocompromised individuals [1-3]. Mostly, candidiasis is attributed to Candida albicans, however; non-albicans Candida species, including C. parapsilosis, C. tropicalis, and C. glabrata, have been reported to cause $30 \%$ to $54 \%$ of Candida infections [4-6]. Furthermore, the ability of these species to exhibit multidrug resistance, which may cause failure of the antifungal therapy, has been reported in earlier studies [6].

The ability of Candida spp to shift the commensal to pathogenic lifestyle is attributed to the presence of several virulence factors. Predominantly, the capability of switching morphology between yeast and hyphal forms, and the ability to form biofilms are the major properties crucial to Candida spp pathogenesis. The Candida infections are accompanied 
by the formation of biofilms on host tissues, organs, or abiotic surfaces such as urinary catheters, which result in high morbidity and mortality [7-9]. As with all microbial biofilms, Candida biofilms are highly resistant to antimicrobial treatment. Several factors might contribute to this resistance, including the physiological state of Candida cells in the biofilm, extracellular polymeric substances, overexpression of membrane-localized drug efflux pumps, variations in sterol content in the fungal membrane, and different developmental phases of cells through the biofilm [10]. Thus, the effectiveness of the current therapeutic agents against Candida biofilms is considered low, with a few exceptions [7-9]. The biofilms of Candida were 30 to 2000 times more resistant than planktonic cells to many antifungal agents, including amphotericin B, fluconazole, itraconazole, and ketoconazole [11]. As a result, the need to provide natural alternatives to these synthetic antifungal agents has arisen. The antifungal mechanisms of action of these natural alternatives can include the inhibition of germination and biofilm formation, the disruption of cell wall integrity, the alteration of cell membrane permeability, or the induction of apoptosis [9].

Caffeic acid phenethyl ester (CAPE), also called phenylethyl caffeate or phenethyl caffeate, is one of the promising natural alternatives of synthetic antimicrobial drugs. This polyphenolic ester compound is a major component of temperate propolis (poplartype) and can be produced in the laboratory by reacting caffeic acid with phenethyl alcohols. It consists of hydroxyl groups within the catechol ring, which is crucial for many biological activities [12,13]. No information was available in the literature about the $\mathrm{LD}_{50}$ of CAPE in animal models or on normal human cells. However, Koru and coworkers investigated cytotoxicity in the human multiple myeloma cell line with $\mathrm{LD}_{50}$ at 24,48 , and $72 \mathrm{~h}$, found at $49.1,30.6$, and $22.5 \mu \mathrm{g} / \mathrm{mL}$, respectively [14]. The CAPE has a wide range of biological activities, such as inhibition of nuclear factor $\mathrm{k}-\mathrm{B}$, cell division restriction, termination of the cell cycle, and apoptotic induction [15]. It has been studied extensively as the most important individual component of propolis. Existing studies focused on its potential therapeutic properties such as its antibiotic, antioxidant, anti-inflammatory, anti-oxidative stress, antitumor, antidiabetic, anti-neurodegeneration, and anti-anxiety properties $[13,16,17]$. Numerous studies demonstrated the antibacterial activity of CAPE against different bacterial species [18-22]. However, few studies that have investigated the antifungal activity of CAPE as a single molecule or in combination with some antibiotics were found in the literature. De Barros and coworkers recently reported the ability of CAPE to inhibit the growth of both fluconazole-sensitive and fluconazoleresistant strains of $C$. albicans [23]. Moreover, Sun and coworkers found the synergistic effects of CAPE with caspofungin and fluconazole against $C$. albicans and fluconazoleresistant $C$. albicans, respectively $[24,25]$. The synergism with caspofungin was associated with a loss in iron homeostasis induced by CAPE, leading to functional defects in the mitochondrial respiratory chain and energy depletion, which increases the susceptibility of C. albicans to caspofungin [25].

Presently, CAPE has been given close attention for its important therapeutic effects in many diseases, including carcinomas, internal organ damage, metabolic diseases, inflammatory diseases, and microbial infections. CAPE may be a promising natural product for clinical application in the future [21]. One of the major advantages is that CAPE is devoid of some negative aspects of crude extracts of propolis, which includes, the inability to be standardized, which is a keystone of implementing it as therapy in the field of medicine [16]. This study aimed to investigate how CAPE, as a single molecule, affects planktonic growth, biofilm-forming abilities, mature biofilms, and cell death of some Candida albicans and non-albicans Candida species and strains.

\section{Results}

\subsection{Susceptibility of Candida Planktonic Cells to CAPE}

The antifungal effect of CAPE on nine Candida strains has been studied. The results of the minimal inhibitory concentration $\left(\mathrm{MIC}_{80}\right.$ ) values for $\mathrm{CAPE}$ against different Candida species and strains are given in Table 1. It has been found that CAPE has a strain- and 
dose-dependent effect. The $\mathrm{MIC}_{80}$ values ranged from 12.5 to $100 \mu \mathrm{g} / \mathrm{mL}$. The highest inhibitory effect was seen against C. glabrata SZMC 1378, C. glabrata SZMC 1374, and C. parapsilosis SZMC 8008 compared with the other strains. However, the most resistant strain was C. albicans SZMC 1423.

Table 1. MIC 80 values of CAPE against the different Candida strains.

\begin{tabular}{cc}
\hline Strain & MIC $_{\mathbf{8 0}}(\mu \mathrm{g} / \mathrm{mL})$ \\
\hline C. albicans ATCC 44829 & 50 \\
C. albicans SZMC 1423 & 100 \\
C. albicans SZMC 1424 & 50 \\
C. glabrata SZMC 1374 & 12.5 \\
C. glabrata SZMC 1378 & 12.5 \\
C. parapsilosis SZMC 8007 & 25 \\
C. parapsilosis SZMC 8008 & 12.5 \\
C. tropicalis SZMC 1366 & 50 \\
C. tropicalis SZMC 1512 & 50 \\
\hline
\end{tabular}

\subsection{Effect of CAPE on Candida Biofilm-Forming Ability}

The biofilm-forming ability is a crucial property related to the pathogenicity of Candida. In this experiment, the effect of CAPE was tested on the biofilms of four different Candida strains with high biofilm-forming abilities. The results demonstrate that CAPE has a dose-dependent inhibitory effect on the biofilm formation in four strains (Figure 1). The minimal biofilm inhibitory concentration (MBIC) values were 50,50, 50, and $100 \mu \mathrm{g} / \mathrm{mL}$ for C. albicans SZMC 1424, C. glabrata SZMC 1374, C. parapsilosis SZMC 8007, and C. tropicalis SZMC 1366, respectively.

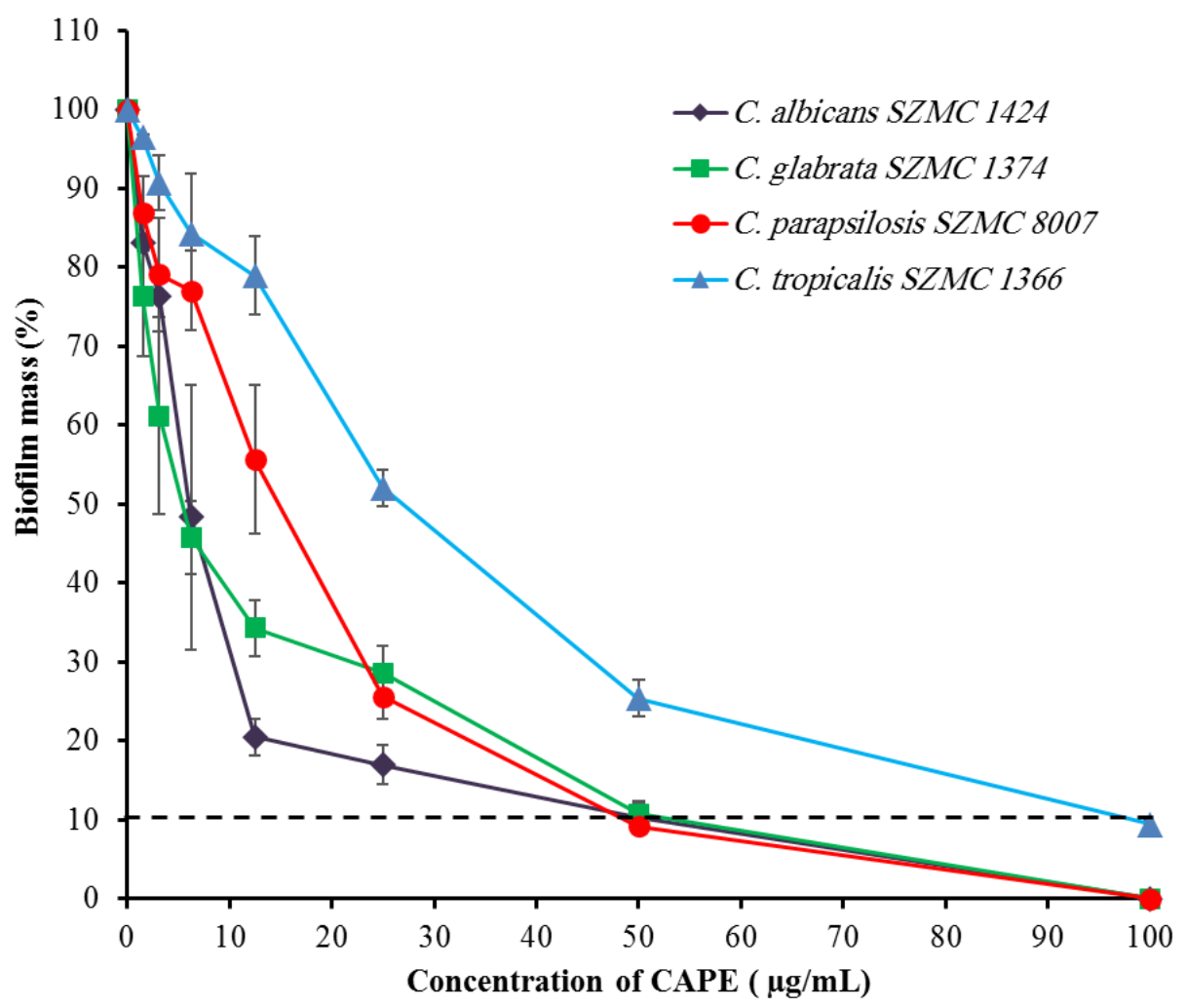

Figure 1. Effect of CAPE on the biofilm-forming ability of four Candida species. The dashed line represents the MBIC. Data are shown as mean \pm SD from three independent experiments. 


\subsection{Effect of CAPE on Candida Biofilm Eradication}

The effect of CAPE on the mature biofilms of four biofilm-forming Candida species was investigated. Treatment of the mature biofilms of $C$. albicans SZMC 1424, C. glabrata SZMC 1374, C. tropicalis SZMC 1366, and C. parapsilosis SZMC 8007 with different concentrations of CAPE caused a partial eradication. The maximum eradications (19-49\%) for the mature biofilms of C. glabrata SZMC 1374, C. albicans SZMC 1424, and C. parapsilosis SZMC 8007 were achieved at 25,50 , and $50 \mu \mathrm{g} / \mathrm{mL}$, respectively. Moreover, the eradication process was found to be dose-independent above $50 \mu \mathrm{g} / \mathrm{mL}$ in the case of these strains. On the other hand, the mature biofilms of $C$. tropicalis SZMC 1366 were the most resistant to CAPE, and the maximum eradication was achieved at $100 \mu \mathrm{g} / \mathrm{mL}$ (Figure 2).

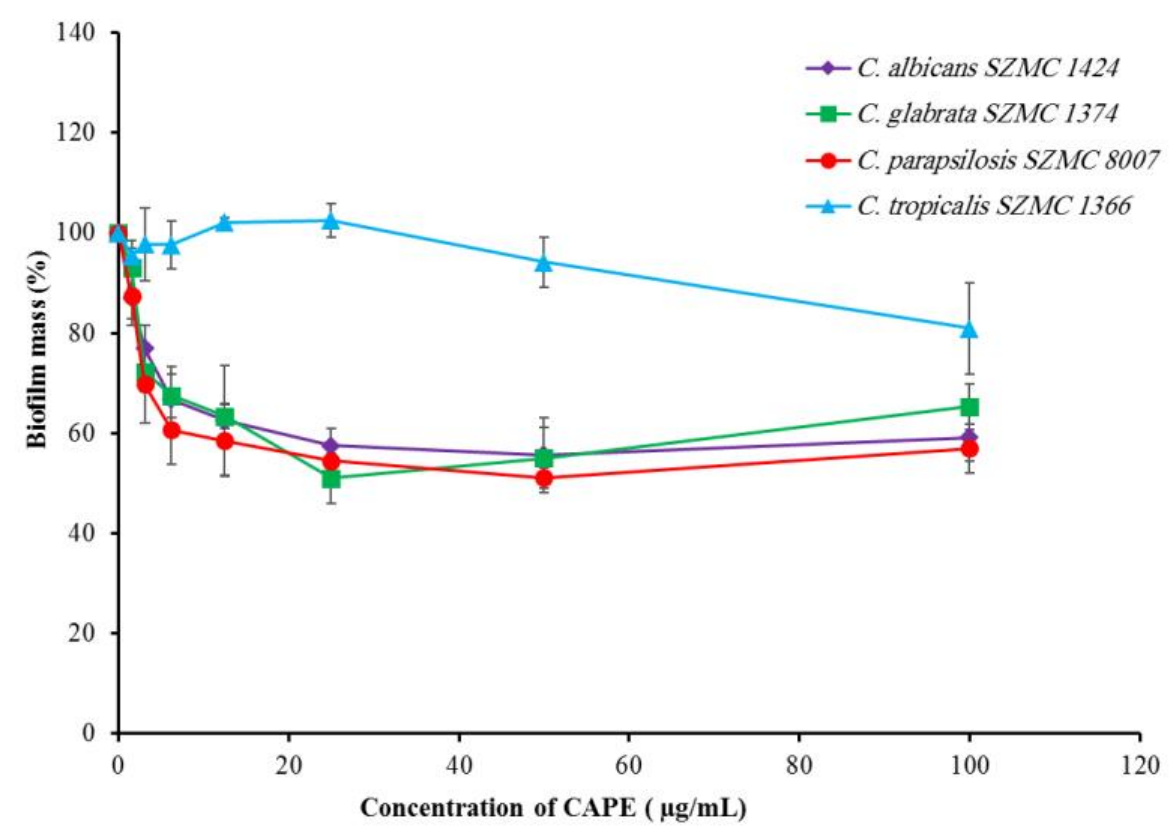

Figure 2. Effect of CAPE on mature biofilms of four Candida species. Data are shown as mean \pm SD from three independent experiments.

\subsection{Biosorption of CAPE by Candida Cells}

Biosorption may be defined as "the removal/binding of desired substances from aqueous solution by biological material" [26]. The results revealed that the biosorption of CAPE by different Candida strains occurs rapidly, followed by a maximum biosorption observed within the first 30 to 90 min (Figure 3). According to the amount of CAPE biosorbed, two groups can be recognized: the first group was able to biosorb $53-63 \mu \mathrm{g} / \mathrm{mL}$ of CAPE, and it includes C. albicans SZMC 1424, C. parapsilosis SZMC 8007, and C. parapsilosis SZMC 8008; in contrast, the second group was able to biosorb $74-86 \mu \mathrm{g} / \mathrm{mL}$, and it includes C. albicans ATCC 44829, C. albicans SZMC 1423, C. tropicalis SZMC 1366, C. tropicalis SZMC 1512, C. glabrata SZMC 1374, and C. glabrata SZMC 1378. 


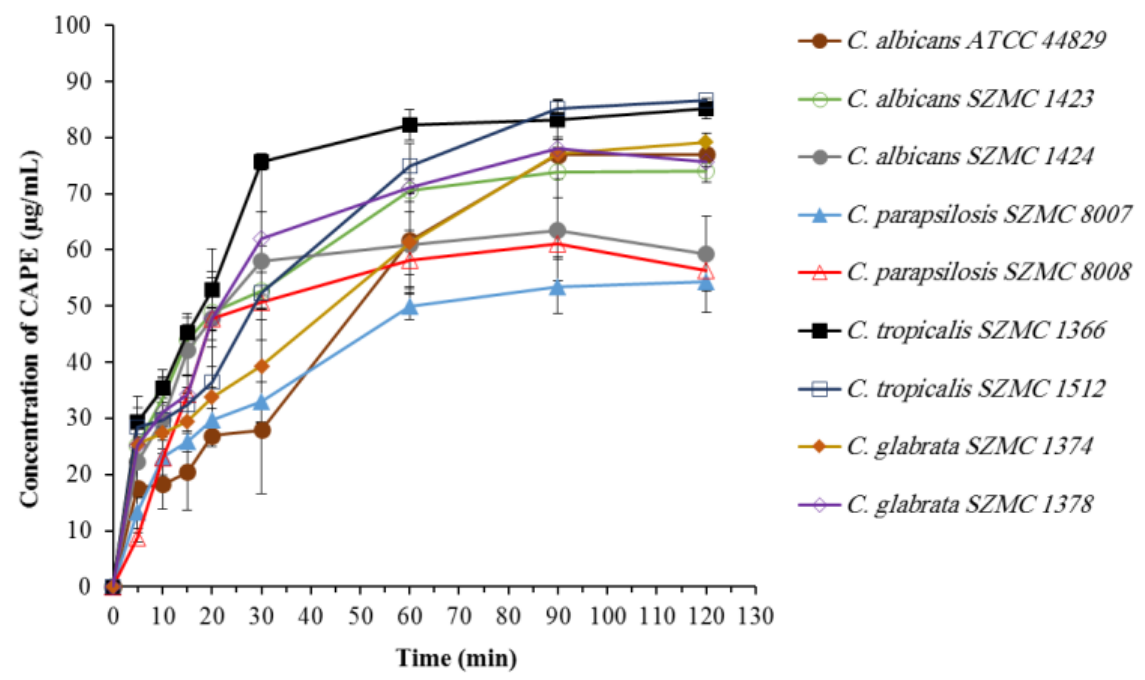

Figure 3. Cellular uptake of CAPE by nine Candida strains. Data are shown as mean $\pm \mathrm{SD}$ from three independent experiments.

\subsection{Induction of Apoptotic Cell Death in Candida spp. by CAPE}

Cells of the nine Candida strains treated with sub-lethal concentrations of CAPE were analyzed by double staining with $\mathrm{CF}^{\circledR} 488 \mathrm{~A}$ Annexin $\mathrm{V}$ and propidium iodide (PI). The apoptotic cells with externalized phosphatidylserine were detected by $\mathrm{CF}^{\circledR} 488 \mathrm{~A}$ Annexin V, while necrotic cells were detected by PI staining. The results shown in Figure 4 demonstrate CAPE-induced apoptosis in six of the tested strains at different levels. Among these strains, C. albicans ATCC 44829 and C. albicans SZMC 1423 revealed the highest percentage of early apoptotic cells (69.8 and $70.2 \%$, respectively), whereas almost no apoptosis was seen in C. glabrata SZMC 1374, C. parapsilosis SZMC 8008, and C. glabrata SZMC 1378 (apoptotic cells $\leq 2 \%$ ). On the other hand, no necrosis was observed in any of the tested strains (necrotic cells $\leq 1 \%$ ). Examples of the scatter plots can be found in the supplementary material (Figures S1-S7).

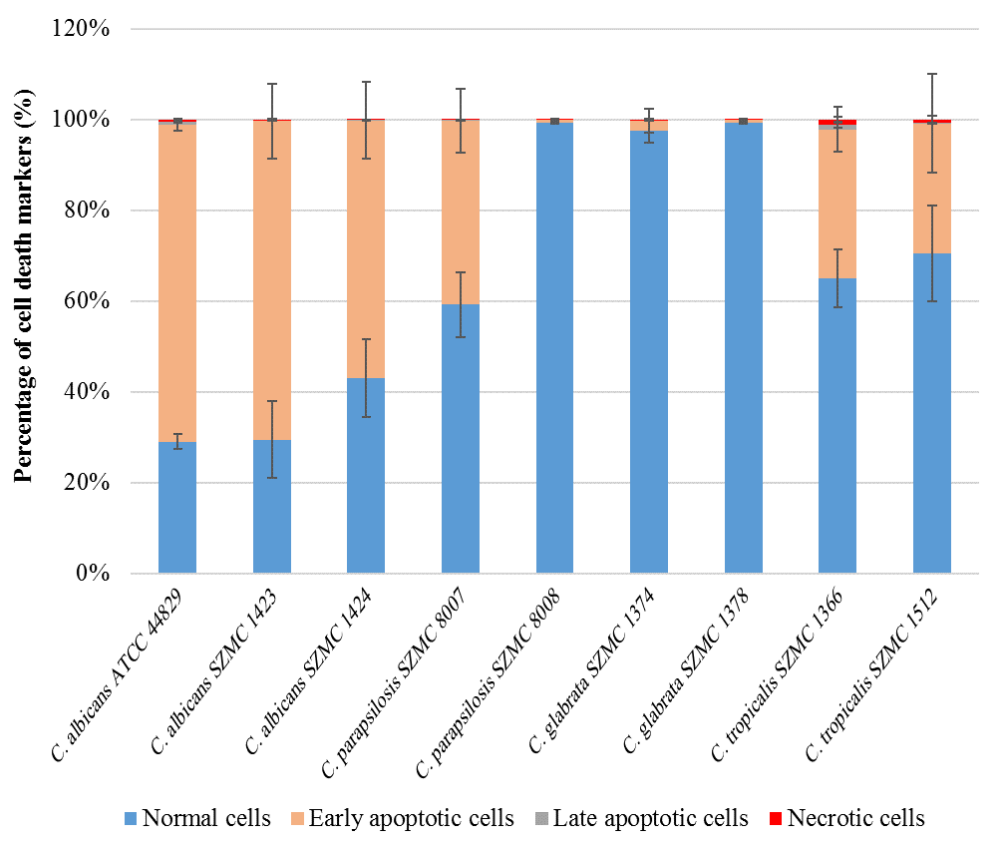

Figure 4. Cell death induced by CAPE treatment in nine Candida strains as determined by annexin V and PI staining. Data are shown as mean \pm SD from three independent experiments. 


\subsection{Effect of Caspase Inhibitor on the Growth of CAPE-Treated Candida Cells}

To investigate whether yeast caspase Yca1p is involved in CAPE-induced apoptotic cell death, pre-incubation with the pan-caspase inhibitor Z-VAD-FMK was applied for $1 \mathrm{~h}$. The growth of the sub-lethal CAPE concentration-treated Candida strains that had apoptosis was analyzed with and without pre-incubation with Z-VAD-FMK. As shown in Figure 5, a significant increase in the viability was observed in C. albicans ATCC 44829, C. albicans SZMC 1424, C. tropicalis SZMC 1366, and C. tropicalis SZMC 1512 that are pre-incubated with the pan-caspase inhibitor Z-VAD-FMK. However, the viability of CAPE-treated C. albicans SZMC 1423 and C. parapsilosis SZMC 8007 was not affected by the pre-incubation with the pan-caspase inhibitor Z-VAD-FMK.

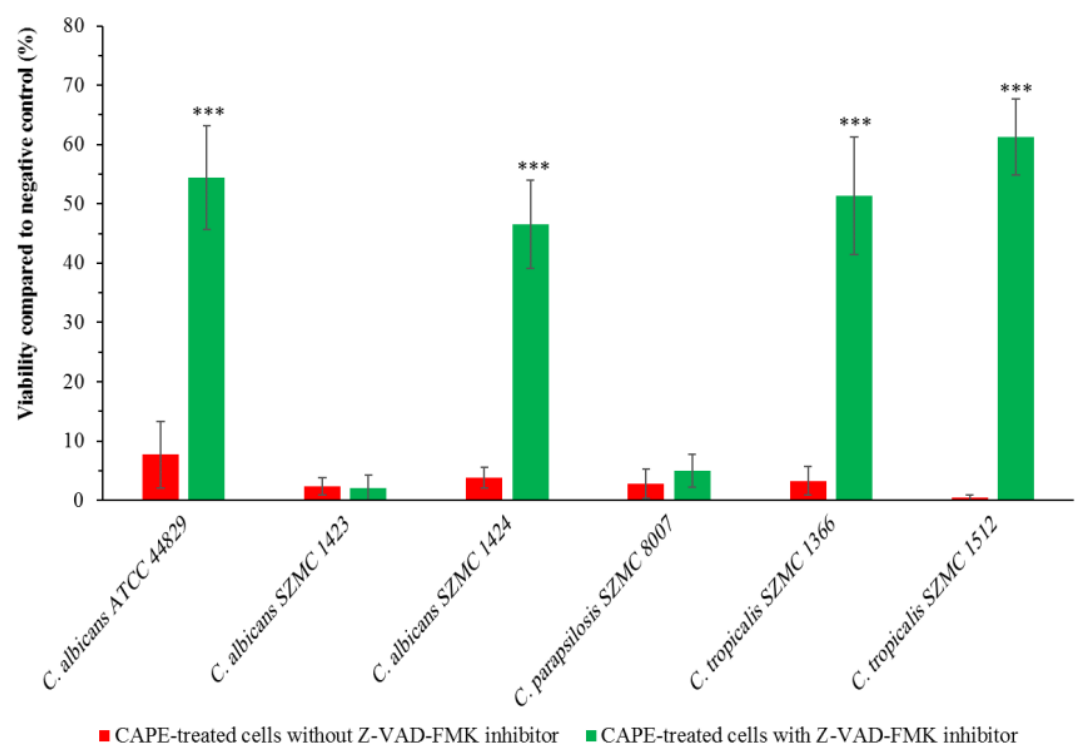

Figure 5. Effect of the pan-caspase inhibitor Z-VAD-FMK on the viability of six Candida strains treated with sub-lethal concentrations of CAPE. Data are shown as mean \pm SD from three independent experiments. ${ }^{* * *} p<0.001$ indicates a significant increment of the viability compared with the viability without pre-incubation with the pan-caspase inhibitor Z-VAD-FMK.

\subsection{CAPE-Induced Subcellular Cell Death Markers Determined by TEM}

To visualize the changes in intracellular morphology of the cells after CAPE treatment, transmission electron microscopy imaging was performed on Candida cells exposed to sub-lethal concentrations of CAPE. The TEM micrographs of C. tropicalis SZMC 1366, C. albicans SZMC 1423, and C. parapsilosis SZMC 8007 (Figures 6-8, respectively) mainly revealed typical hallmarks of apoptosis, including nuclear chromatin margination, nuclear blebs, condensation in the nucleus, vacuolization, plasma membrane detachment, enlarged lysosomes, cytoplasm fragmentation, cell wall distortion, and whole-cell shrinkage. However, very few cells displayed signs of necrosis, such as membrane disintegration and loss of cytoplasm density, whereas the TEM micrographs of C. glabrata SZMC 1374 (Figure 9) mainly revealed smaller necrotic signs. 

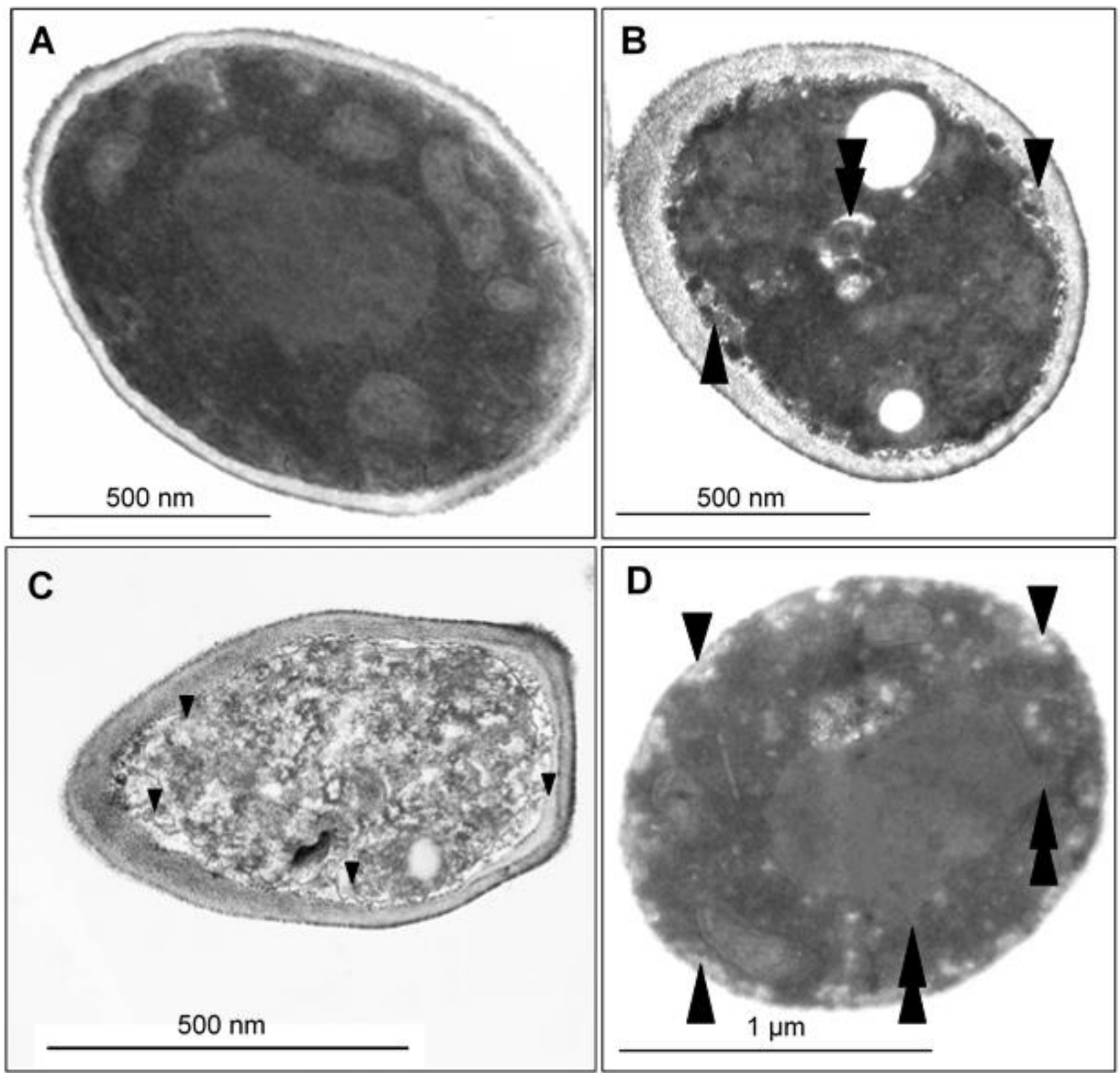

Figure 6. (A) TEM micrographs of the control Candida tropicalis SZMC 1366 cell structure demonstrates intact membranes, small unevenly scattered condensed chromatin grains, and homogenous cytoplasm structure. (B-D) TEM micrographs of $C$. tropicalis treated with a sub-lethal concentration of CAPE: (B) Late-stage disintegration with membrane fingerprints, vacuolization, plasma membrane detachment (arrowheads), and vacuole formation (double arrowheads). Fine granular homogenous cytoplasm organization disappeared, and a dense, compact cytoplasm with signs of fragmentation, rounded cell shape, and whole-cell shrinkage was seen. (C) Necrotic cell with membrane ruptures (arrowheads) and loss of cytoplasm density. (D) Several peripheral vacuoles show plasma membrane involvement (arrowheads). Nuclear bleb formation (double arrowheads). 

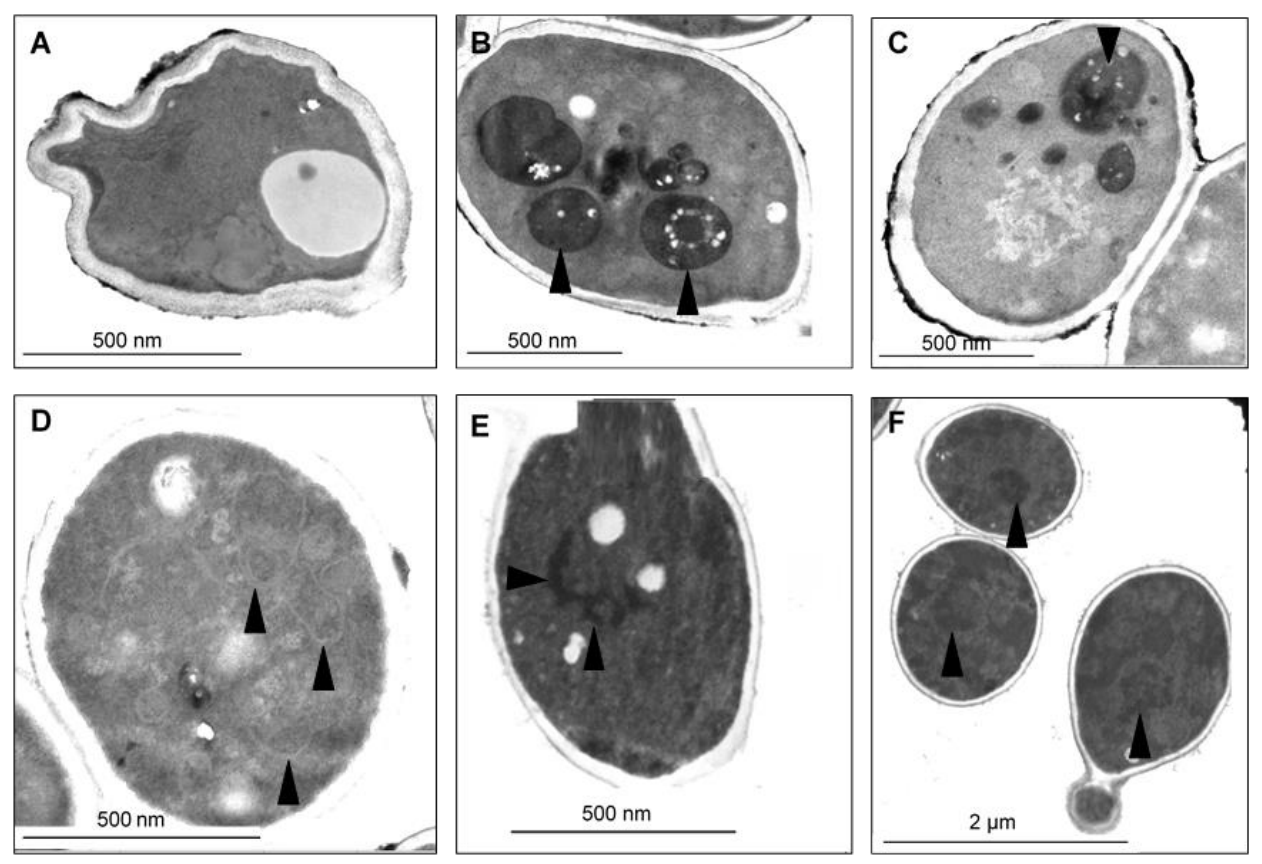

Figure 7. TEM micrographs of C. albicans SZMC 1423 treated with a sub-lethal concentration of CAPE exhibit different markers of cellular deterioration. (A) Severe cell wall distortion. (B,C) Appearance of enlarged lysosomes was rather frequently detected (arrowheads). (D) Isolation membranes precondition of cytoplasm fragmentation (arrowheads). (E,F) Nucleus fragmentation and marginal condensation (arrowheads).
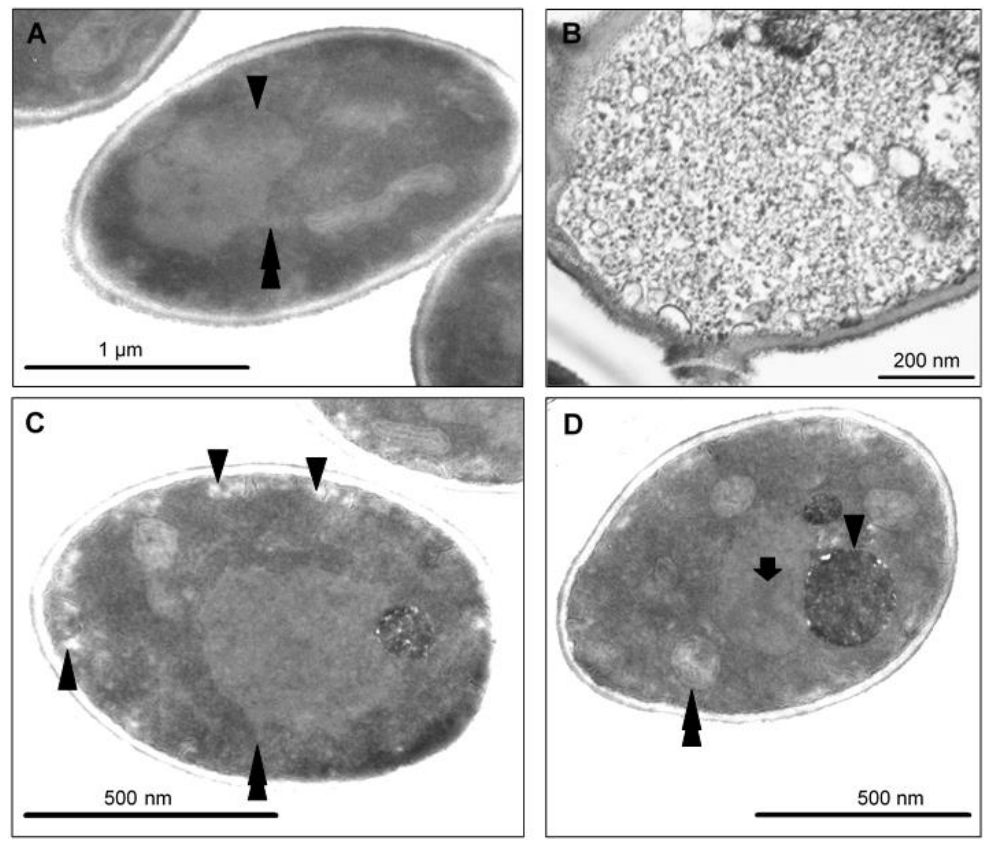

Figure 8. TEM micrographs of C. parapsilosis SZMC 8007 treated with a sub-lethal concentration of CAPE. Both apoptotic and necrotic cell structural changes were observed in samples. (A) Nuclear chromatin margination and condensation (arrowhead) and blebs (double arrowhead) detached from the nucleus are typical apoptotic hallmarks. (B) Few necrotic cells were also present. Note membrane disintegration, obvious vacuolization, and loss of cytoplasm density. (C) Peripheral vacuole formation refers to Golgi fragmentation and cell membrane separation from the cell wall (arrowheads). Nuclear blebs (double arrowhead). (D) Nuclear condensation (arrow) and extremely large lysosomal bodies (arrowhead). Note the swollen mitochondria (double arrowheads). 

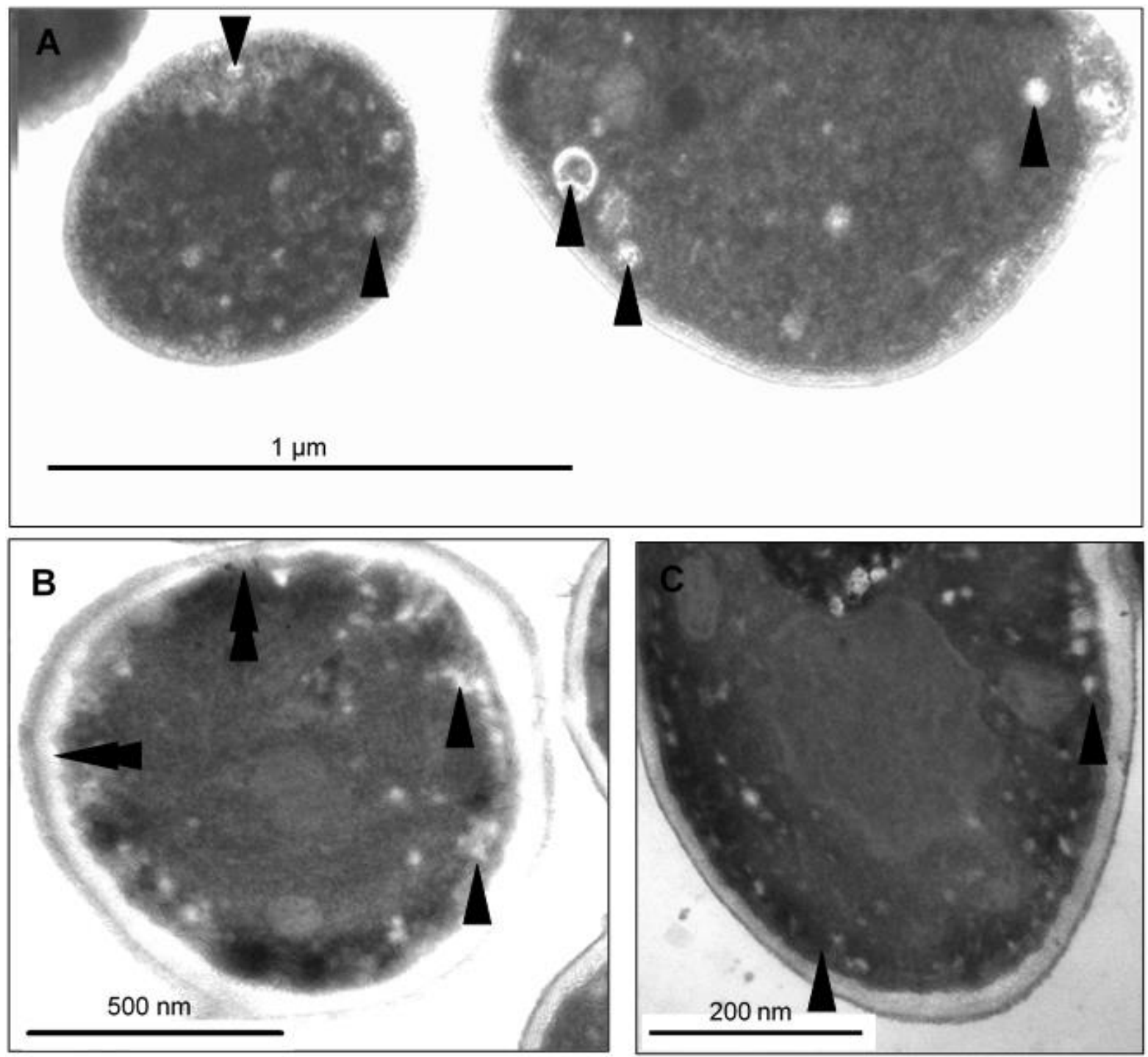

Figure 9. TEM micrographs of C. glabrata SZMC 1374 treated with a sub-lethal concentration of CAPE. (A-C) Mainly smaller necrotic signs were detected. Arrowheads denote small, mainly peripheral vacuoles typical of all samples. (B) Cell wall disintegration was also observed (double arrowhead).

\section{Discussion}

This study focused on the antifungal and anti-biofilm effects of CAPE, which is one of the main biologically active components of propolis, on different Candida species including C. albicans and non-albicans Candida species. Moreover, we also investigated some of the mechanisms that might be involved in CAPE-induced cell death.

The Candida spp are still considered the most important opportunistic fungal pathogens that cause fungal infections worldwide. They are among the fourth to sixth most common nosocomial bloodstream isolates, according to estimates. Although $C$. albicans was the most frequent species isolated during candidemia, a greater role of non-albicans Candida spp has been observed in recent years [6,27]. Moreover, the extensive use of azole antifungals has resulted in the development of multidrug resistance in many Candida strains [28,29]. This resistance could be attributed to a change in drug intracellular accumulation, a change in membrane sterol composition, a change in efflux pump performance, or a change in ERG11 (the gene that is responsible for the production of the lanosterol-14-demethylase enzyme, the target of these medications) [6]. 
The biological activities of CAPE have been widely studied. However, limited number of studies were found in the literature concerning the antifungal activity. This study aimed to add some information about the activity of CAPE against $C$. albicans and non-albicans Candida species. Our findings showed that CAPE has high abilities to inhibit planktonic growth and biofilm formation as well as an ability to partially eradicate the mature biofilms of the different strains of Candida. Those results are in agreement with the results obtained by De Barros and coworkers, where the ability of CAPE to inhibit the growth of both fluconazole-sensitive and fluconazole-resistant strains of C. albicans has been reported [23]. Another study performed by Possamai Rossatto and coworkers showed similar results, where CAPE was also able to inhibit the growth of $C$. auris with MIC values ranging from 1 to $64 \mu \mathrm{g} / \mathrm{mL}$. Furthermore, CAPE was able to inhibit the biofilm formation and phospholipase production of C. auris [30]. Our findings also showed the ability of CAPE to enter the cells of Candida spp rapidly. Such results were also observed by Cigut and coworkers in the yeast Saccharomyces cerevisiae. They found that, out of the four examined compounds (caffeic acid, p-coumaric acid, ferulic acid, and CAPE), CAPE was the only one that was able to enter the $S$. cerevisiae cells [31].

Phenolic compounds, including CAPE, are effective inhibitors of iron absorption [25]. According to Sun and coworkers, the antifungal mechanism of CAPE may include intracellular iron starvation due to its ability to form insoluble complexes with iron ions, which leads to the prevention of iron absorption by cells [25]. Using C. albicans-infected nematodes, Breger and coworkers showed that CAPE was able to inhibit the in vivo filamentation of C. albicans, leading to prolonged survival of infected nematodes [32]. Other studies attributed the antifungal activity of CAPE to its action on RNA, DNA, and cellular proteins, which are probable targets of this compound [13]. On the other hand, $\mathrm{Su}$ and coworkers suggested that the cytotoxicity of CAPE could be related to its apoptotic effect on the cells [33]. Marin and coworkers found that CAPE was able to induce the genes that are responsible for apoptosis and oxidative stress response. They reported that some polyphenolic compounds may have pro-oxidant activity, which can induce oxidative stress in the cells through the production of high levels of reactive oxygen species or inhibition of the system antioxidants [34]. In our study, we found that CAPE can induce apoptosis in five Candida strains, which are C. albicans ATCC 44829, C. albicans SZMC 1423, C. albicans SZMC 1424, C. parapsilosis SZMC 8007, C. tropicalis SZMC 1366, and C. tropicalis SZMC 1512. Surprisingly, C. parapsilosis SZMC 8007, C. glabrata SZMC 1374, and C. glabrata SZMC 1378 did not exhibit apoptotic cell death, which indicates that different species of Candida and, in one case, different strains of the same species have different cell death responses to CAPE. Moreover, the TEM images of CAPE-treated Candida cells showed the typical hallmarks of apoptosis in most Candida species. Notably, the apoptotic hallmarks were almost the same in different Candida species. Similar apoptotic hallmarks have been reported by several previous studies on C. albicans. De Nollin and Borgers (1975) reported the alterations of the surface micromorphology in C. albicans after treatment with miconazole. Shrinkage of protoplasm, abnormal cell and nuclear morphology, and vacuolization were also observed in plantaricin peptide-treated cells of C. albicans [35]. Distortion of the cell walls and membranes, which caused alterations of the surface micromorphology, could be explained due to a change in the permeability of the cell membrane, which could cause an osmotic imbalance, leading to alterations and indentations of the cell wall in collapsed cells [36].

Furthermore, we investigated the mechanisms involved in CAPE-induced apoptosis in Candida spp. Application of the broad-range pan-caspase inhibitor Z-VAD-FMK significantly reduced CAPE-induced apoptosis in C. albicans ATCC 44829, C. albicans SZMC 1424, C. tropicalis SZMC 1366, and C. tropicalis SZMC 1512. Such results suggest that this compound induced yeast caspase (Yca1p)-dependent apoptosis in these strains. Since CAPE can increase the permeability of the plasma membrane to ions [20], it can cause depolarization in mitochondria. This could lead to the release of cytochrome $\mathrm{c}$ and other proapoptotic factors into the cytosol, which in turn leads to the activation of yeast metacaspase Yca1p, resulting in the activation of caspase cascade inducing apoptosis [37]. However, 
the pre-incubation of CAPE-treated C. albicans SZMC 1423 and C. parapsilosis SZMC 8007 with the pan-caspase inhibitor Z-VAD-FMK did not affect their viability, which means that the CAPE-induced apoptosis in these strains was Yca1p-independent. This suggests that it could be due to the release of the apoptosis-inducing factor Aif1p from the mitochondria triggered by CAPE. These results support the fact that CAPE not only has species- and strain-dependent cell death responses in Candida but also could induce apoptotic cell death through different mechanisms.

\section{Materials and Methods}

\subsection{Materials}

For our experiments, CAPE (Sigma-Aldrich, Buchs, Switzerland); sodium dodecyl sulfate; crystal violet; peptone; yeast extract (Merck, Germany); agar-agar (Fluka, Buchs, Switzerland); a modified version of RPMI 1640 medium (containing dextrose 1.8\% (w/v), MOPS 3.4\% $(w / v)$, and adenine $0.002 \%(w / v))$ (Sigma-Aldrich, St. Louis, MI, USA); potassium dihydrogen phosphate; disodium hydrogen phosphate (Reanal, Budapest, Hungary); dimethyl sulfoxide; ethanol (VWR Chemicals, Paris, France); sodium chloride (VWR Chemicals, Debrecen, Hungary); glucose (VWR Chemicals, Leuven, Belgium); adenine; calcium chloride; magnesium chloride; potassium chloride (Scharlau Chemie S.A, Sentmenat, Spain); Z-VAD-FMK (Biovision, Milpitas, CA, USA); glutardialdehyde solution; osmium tetroxide; propylene oxide; Durcupan (R) ACM components A/M, B, C, and D (Sigma-Aldrich, Darmstadt, Germany); $0.22 \mu \mathrm{m}$ vacuum filters (Merck Millipore, Guyancourt, France); sterile 96-well microtiter plates for susceptibility testing (Costar ${ }^{\circledR}$, Phoenix, AZ, USA) and for biofilm assays (Sarstedt AG \& Co. KG, Nümbrecht, Germany, Catalog number: 83.3924.500); CF ${ }^{\circledR} 488 \mathrm{~A}$ Annexin V and PI apoptosis Kit (Biotium, Fremont, CA, USA); and methanol (Chemolab Ltd., Budapest, Hungary) were used. All of the chemicals used in the experiments were of analytical or spectroscopic grade.

\subsection{Instruments Used in the Experiments}

A Thermo Scientific Heraeus B12 incubator (Thermo Fisher Scientific, Waltham, MA, USA), Sanyo orbital incubator (Sanyo, Japan), Sanyo autoclave (Sanyo, Japan), Hitachi U-2910 UV/Vis spectrophotometer (Hitachi, Japan), WTW pH meter (inoLab, Germany), Multiskan EX plate reader (Thermo Fisher Scientific Inc., Vantaa, Finland), benchtop centrifuge (Hettich, Buford, GA, USA), Ultramicrotome Reichert Jung Ultracut E (LabX, Midland, ON, Canada), JEOL-1200EX Transmission electron microscope (TEM), and Attune NxT flow cytometer (Thermo Fisher Scientific Inc., Massachusetts, USA) were used throughout the experiments.

A Thermo Scientific Heraeus B12 incubator (Thermo Fisher Scientific, Waltham, MA, USA), Sanyo orbital incubator (Sanyo, Japan), Sanyo autoclave (Sanyo, Japan), Hitachi U-2910 UV/Vis spectrophotometer (Hitachi, Japan), WTW pH meter (inoLab, Germany), Multiskan EX plate reader (Thermo Fisher Scientific Inc., Vantaa, Finland), benchtop centrifuge (Hettich, USA), Ultramicrotome Reichert Jung Ultracut E (LabX, Canada), JEOL1200EX Transmission electron microscope (TEM), and Attune NxT flow cytometer (Thermo Fisher Scientific Inc., Massachusetts, USA) were used throughout the experiments.

\subsection{Test Microorganisms, Culture Media, and Growth Conditions}

Four species of Candida were used: C. albicans, C. tropicalis, C. glabrata, and C. parapsilosis. Nine strains were included, one of which was the American Type Culture Collection (ATCC) strain, and the others were Candida isolates obtained from Szeged Microbial Collection (SZMC), University of Szeged, Hungary (Table 2). All strains were maintained at the Department of General and Environmental Microbiology, Institute of Biology, University of Pécs, Hungary. All strains were grown in yeast extract peptone dextrose (YPD) broth (yeast extract $1 \%$, peptone $2 \%$, and glucose $2 \%$ in distilled water, $\mathrm{pH} 6.8$ ) or on YPD plates. 
Table 2. Candida species and strains used in the study.

\begin{tabular}{lccc}
\hline Species & Collection Code & Origin & Biofilm-Forming Ability \\
\hline C. albicans & ATCC 44829 & $\begin{array}{c}\text { auxotrophic mutant isolated after N-methyl } \\
\text { N'-nitro-N-nitrosoguanidine treatment of a } \\
\text { wild-type strain of C. albicans. }\end{array}$ & Non-biofilm forming \\
C. albicans & SZMC 1423 & clinical sample/Debrecen, Hungary & Non-biofilm forming \\
C. albicans & SZMC 1424 & clinical sample/Debrecen, Hungary & High-biofilm forming \\
C. tropicalis & SZMC 1366 & hemoculture/Debrecen, Hungary & High-biofilm forming \\
C. tropicalis & SZMC 1512 & -/Pécs, Hungary & Non-biofilm forming \\
C. glabrata & SZMC 1374 & clinical sample/Debrecen, Hungary & High-biofilm forming \\
C. glabrata & SZMC 1378 & clinical sample/Debrecen, Hungary & Non-biofilm forming \\
C. parapsilosis & SZMC 8007 & clinical sample/Szeged, Hungary & High-biofilm forming \\
C. parapsilosis & SZMC 8008 & unknown & Non-biofilm forming \\
\hline
\end{tabular}

\subsection{Preparation of Stock Solution of CAPE}

The stock solution was freshly prepared by dissolving CAPE in ethanol at a concentration of $10 \mathrm{mg} / \mathrm{mL}$. The stock solution was kept in the freezer at $-20{ }^{\circ} \mathrm{C}$.

\subsection{Antifungal Susceptibility Testing}

The broth microdilution method was performed to determine the minimal inhibitory concentration $\left(\mathrm{MIC}_{80}\right)$ according to the protocol of the National Committee for Clinical Laboratory Standards Institute with some modifications [38]. Briefly, a standardized initial inoculum $\left(10^{6}\right.$ cells $\left./ \mathrm{mL}\right)$ was applied in all experiments. The experiments were performed in sterile, flat-bottom 96-well microplates. To obtain final CAPE concentrations ranging from 400 to $3.125 \mu \mathrm{g} / \mathrm{mL}$, equal volumes $(100 \mu \mathrm{L})$ of cell suspension and CAPE-containing YPD medium were added into the wells. Negative controls (media and cell suspension without CAPE) and blanks (media with CAPE) were included in each experiment. The concentration of the solvent was constantly fixed at $1 \%$. The plates were incubated at $35^{\circ} \mathrm{C}$, and the absorbance was measured after $48 \mathrm{~h}$ at $600 \mathrm{~nm}$ using a Multiskan EX plate reader. The $\mathrm{MIC}_{80}$ of CAPE was determined as the lowest concentration that causes an $80 \%$ reduction in the growth when compared with that of the negative control.

\subsection{Biofilm-Forming Ability Assay}

Biofilm formation assay was performed using the crystal violet staining method as described previously [39]. To inoculate the test microplates, a stationary-phase yeast culture was prepared using an inoculum size equivalent to $0.5 \mathrm{McF}$ arland standard. The culture was shaken thoroughly and then diluted at 1:100 using RPMI-1640 medium. A series of two-fold dilutions were prepared from the stock solution of CAPE. In the test microplates, equal volumes $(100 \mu \mathrm{L})$ of each dilution were added to identical volumes $(100 \mu \mathrm{L})$ of the diluted cell suspensions to obtain final concentrations from 100 to $1.562 \mu \mathrm{g} / \mathrm{mL}$ CAPE in the wells. In each experiment, the negative controls and blanks were included. The concentration of the solvent was constantly fixed at $1 \%$. The microplates were kept in an incubator at $35^{\circ} \mathrm{C}$ for $48 \mathrm{~h}$; afterward, the liquid part was discarded and the remaining biofilms were repeatedly washed with phosphate-buffered saline (PBS) ( $\mathrm{pH}$ 7.4). Formalin in PBS $2 \%(v / v)$ was used to fix the biofilms; then, the crystal violet $0.13 \%(w / v)$ staining was applied for $20 \mathrm{~min}$ at room temperature. The excess crystal violet stain was discarded, and the wells were washed thoroughly and repeatedly with PBS buffer. The estimation of biofilm mass was conducted by adding sodium dodecyl sulfate (SDS) in ethanol ( $1 \% w / v)$ solution to each well to extract the stain overnight, and the absorbance of the solution was measured at $600 \mathrm{~nm}$ using a Multiskan EX plate reader. The minimum biofilm inhibitory concentration (MBIC) was defined as the lowest concentration of CAPE that was able to inhibit $90 \%$ of the biofilm-forming ability. 


\subsection{Biofilm Eradication Assay}

The effect of CAPE on mature biofilms was verified as described by Nostro and coworkers [40]. Briefly, for the inoculation of the assay microplates, stationary-phase yeast cultures were prepared using an inoculum size equivalent to $0.5 \mathrm{McFarland}$ standard and thereafter diluted 1:100 using RPMI-1640 medium. Microplates containing diluted cell suspension were kept in an incubator at $35{ }^{\circ} \mathrm{C}$ for $48 \mathrm{~h}$. After the biofilm maturation, CAPE treatment was applied. Accordingly, the original RPMI culture was discarded and replaced with a CAPE-containing RPMI medium with concentrations ranging from 100 to $1.562 \mu \mathrm{g} / \mathrm{mL}$. Negative controls and blanks were included in each experiment. The concentration of the solvent was constantly fixed at $1 \%$. After $48 \mathrm{~h}$ of incubation at $35^{\circ} \mathrm{C}$, the liquid part of the media was discarded, and the remaining biofilms were washed, fixed, stained, and estimated as mentioned in the previous section (Section 4.6).

\subsection{Biosorption of CAPE by Candida Cells}

To determine the cellular biosorption of CAPE, YPD broth cultures of Candida strains were grown overnight at $35^{\circ} \mathrm{C}$ and $150 \mathrm{rpm}$ in an orbital shaker. The number of yeast cells was adjusted to $10^{7}$ cells $/ \mathrm{mL}$ in each case, and the cultures were treated with $100 \mu \mathrm{g} / \mathrm{mL}$ $\mathrm{CAPE}$ and incubated at $35^{\circ} \mathrm{C}$ with shaking at $150 \mathrm{rpm}$. The concentration of the solvent was constantly fixed at $1 \%$. Samples were taken at the time points $0,5,10,15,20,30,60$, and $120 \mathrm{~min}$ after admission and centrifuged ( $5000 \mathrm{rpm}, 5 \mathrm{~min}$ ), and the absorbance of the cell-free supernatants was measured at $330 \mathrm{~nm}$ (absorption maximum of CAPE) using a Hitachi U-2910 UV/Vis spectrophotometer. A calibration curve of two-fold serial dilutions of CAPE from 100 to $0.781 \mu \mathrm{g} / \mathrm{mL}$ was constructed and used to evaluate the biosorption levels of Candida cells [41].

\subsection{Cell Death Examination Assay}

The YPD broth media were inoculated with Candida cells $\left(10^{6} \mathrm{cell} / \mathrm{mL}\right)$ from fresh YPD plate cultures and incubated at $35^{\circ} \mathrm{C}$ with shaking at $150 \mathrm{rpm}$ until reaching the mid-exponential phase depending on their growth curves. Media containing sub-lethal concentrations $\left(\mathrm{MIC}_{80}\right)$ of CAPE were inoculated with $2.5 \times 10^{6}$ cells $/ \mathrm{mL}$ of the midexponential phase cultures of different Candida species and strains and incubated at $35^{\circ} \mathrm{C}$ with shaking for $3 \mathrm{~h}$. Untreated cell samples were included as negative controls in each experiment. The concentration of the solvent was constantly fixed at $1 \%$ in all experiments. After the incubation period, cells were harvested and washed with PBS. The $\mathrm{CF}^{\circledR} 488 \mathrm{~A}$ Annexin V and PI apoptosis Kit was used according to the manufacturer's instructions to identify apoptosis and necrosis. In brief, Candida cells were re-suspended in $1 \mathrm{X}$ annexin V binding buffer at a concentration of $5 \times 10^{6}$ cells $/ \mathrm{mL}$. To $100 \mu \mathrm{L}$ of this solution, $5 \mu \mathrm{L}$ of $\mathrm{CF}^{\circledR} 488 \mathrm{~A}$ Annexin $\mathrm{V}$ and $2 \mu \mathrm{L}$ of PI working solution were added. The tubes were gently vortexed and incubated for 20 minutes at room temperature in the dark. After incubation, $400 \mu \mathrm{L}$ of $1 \mathrm{X}$ annexin $\mathrm{V}$ binding buffer was added to each tube and analyzed using an Attune NxT flow cytometer. Annexin V is responsible for the detection of phosphatidylserine translocation from the inner to outer leaflets of the plasma membrane, whereas PI is a membrane-impermeant DNA-binding dye that is usually used to selectively stain dead cells in a cell population. PI is excluded by living cells and early apoptotic cells but stains necrotic and late apoptotic cells with compromised membrane integrity.

\subsection{Caspase Inhibitor Assay}

Caspase inhibitor assay was performed as described by Yue and coworkers [42] with some modifications. Briefly, cells were divided into two groups. The first group was pretreated for $1 \mathrm{~h}$ at $35^{\circ} \mathrm{C}$ with the broad-spectrum caspase inhibitor Z-VAD-FMK (final concentration $77 \mu \mathrm{M}$ ) before incubation with CAPE. The second group was used as a control (not treated with the caspase inhibitor). For microplate assays, the cells were harvested by centrifugation, washed twice with PBS, and then re-suspended in YPD broth. The cell density was adjusted to $2 \times 10^{6}$ cell $/ \mathrm{mL}$. Equal volumes $(100 \mu \mathrm{L})$ of cell suspension 
and CAPE-containing YPD medium were dispensed into the wells to obtain the final CAPE concentration equal to the $\mathrm{MIC}_{80}$ of each strain. Negative controls (media and cell suspension without CAPE) and blanks (media with CAPE) were included in each experiment. The concentration of the solvent was constantly fixed at $1 \%$. The plates were incubated at $35{ }^{\circ} \mathrm{C}$, and the absorbance was measured after $48 \mathrm{~h}$ at $600 \mathrm{~nm}$ using a Multiskan EX plate reader.

\subsection{Ultrastructural Examination of Candida Species by TEM}

Media containing sub-lethal concentrations of CAPE were inoculated with $2.5 \times 10^{6}$ cells $/ \mathrm{mL}$ of the mid-exponential phase cultures of different species of Candida and incubated at $35^{\circ} \mathrm{C}$ with shaking for $3 \mathrm{~h}$ to induce apoptosis. After the incubation period, the cells were harvested by centrifugation ( $5000 \mathrm{rpm}, 5 \mathrm{~min}$ ). The pellets were immediately washed and re-suspended with modified PBS (a mixture of $50 \mathrm{mM} \mathrm{K}_{2} \mathrm{HPO}_{4}$ and $\mathrm{KH}_{2} \mathrm{PO}_{4}$ (pH 7.0), supplemented with $0.5 \mathrm{mM} \mathrm{MgCl} 2$ ) and incubated at room temperature for 15 min to achieve equilibrium. Then, the samples were fixed overnight in $2.5 \%$ glutaraldehyde fixative buffered with modified PBS. The samples were then washed 4 times with modified PBS, and after short centrifugal sedimentation (1000 rpm, $2 \mathrm{~min}$ ) preparation continued with a $2 \%$ osmium tetroxide post-fixation on ice for $2 \mathrm{~h}$. The cells were then washed twice with distilled water for $15 \mathrm{~min}$ and stained 'en bloc' in 1\% aqueous uranyl acetate for $30 \mathrm{~min}$. After two further washing steps with distilled water and short sedimentation, the cells were dehydrated in 70,96 , and $100 \%$ ethanol for 15 min each, subsequently. The cells were treated with propylene oxide twice for $10 \mathrm{~min}$ each time and then infiltrated for $1 \mathrm{~h}$ in a propylene oxide/Durcupan epoxy resin mixture (1:1) at room temperature. After $1 \mathrm{~h}$, the cells were transferred to fresh epoxy resin drops for another $1 \mathrm{~h}$. The resin was then changed, and the samples were left overnight in the fresh resin drops at room temperature. On the next day, the resin was changed twice while incubating at $40{ }^{\circ} \mathrm{C}$ for $2 \mathrm{~h}$, subsequently. Finally, the samples were encapsulated in fresh epoxy resin and left at $56{ }^{\circ} \mathrm{C}$ for a two-day-long polymerization. Serial ultrathin sections were cut with Reichert Ultramicrotome, collected onto 300 mesh Nickel grids, counterstained on drops of uranyl acetate and Reynolds solution of lead citrate, washed thoroughly in sterile distilled water, and examined with a JEOL-1200 EX TEM at $80 \mathrm{KeV}$ [43].

\subsection{Statistical Analysis}

All assays were carried out in triplicate, and data were expressed as mean \pm standard deviation (SD). For data processing and visualization of the results, Microsoft Office Excel 2016 was used. Data were statistically analyzed through two-sample t-tests using Past3.21 software (University in Oslo, Oslo, Norway).

\section{Conclusions}

CAPE could be considered a promising natural antifungal agent. It has a concentrationand strain-dependent effect on the viability and biofilm-forming ability of the different Candida species. Moreover, it has a partial ability to eradicate the mature biofilms of biofilmforming strains of Candida. In most Candida species and strains, the antifungal mechanism involves the induction of apoptotic cell death in treated cells. However, in other Candida species and strains, no apoptotic cell death was observed. This information suggests that CAPE may have a species- and strain-dependent cell death response in Candida.

Supplementary Materials: The following are available online at https:/ / www.mdpi.com/article/ 10.3390/antibiotics10111359/s1, Figure S1: Representative flow cytometry scatter plot showing apoptosis of C. albicans ATCC 44829 treated with $50 \mu \mathrm{g} / \mathrm{mL}$ of CAPE, Figure S2: Representative flow cytometry scatter plot showing apoptosis of C. albicans SZMC 1423 treated with $100 \mu \mathrm{g} / \mathrm{mL}$ of CAPE, Figure S3: Representative flow cytometry scatter plot showing apoptosis of C. albicans SZMC 1424 treated with $50 \mu \mathrm{g} / \mathrm{mL}$ of CAPE, Figure S4: Representative flow cytometry scatter plot showing apoptosis of C. parapsilosis SZMC 8007 treated with $25 \mu \mathrm{g} / \mathrm{mL}$ of CAPE, Figure S5: Representative flow cytometry scatter plot showing apoptosis of C. parapsilosis SZMC 8008 treated with $12.5 \mu \mathrm{g} / \mathrm{mL}$ 
of CAPE, Figure S6: Representative flow cytometry scatter plot showing apoptosis of C. glabrata SZMC 1374 treated with $12.5 \mu \mathrm{g} / \mathrm{mL}$ of CAPE, Figure S7: Representative flow cytometry scatter plot showing apoptosis of C. glabrata SZMC 1378 treated with $12.5 \mu \mathrm{g} / \mathrm{mL}$ of CAPE.

Author Contributions: Conceptualization, I.A. and G.P.; methodology, I.A., A.V. and E.P.; validation, I.A, E.P. and G.P.; formal analysis, all authors; investigation, I.A. and E.P.; resources, I.A., E.P., A.V. and G.P.; data curation, I.A.; writing—original draft preparation, I.A. and G.P.; writing-review and editing, I.A., E.P., Á.C., A.V., S.D. and G.P.; visualization, I.A., E.P., Á.C., A.V., S.D. and G.P.; supervision, G.P. and I.A.; project administration, G.P. All authors have read and agreed to the published version of the manuscript.

Funding: This research received no external funding.

Institutional Review Board Statement: Not applicable.

Informed Consent Statement: Not applicable.

Data Availability Statement: Not applicable.

Acknowledgments: This research was also connected to the project GINOP-2.3.3-15-2016-00006 (Széchenyi 2020 Programme).

Conflicts of Interest: The authors declare no conflict of interest.

\begin{abstract}
Abbreviations
CAPE: Caffeic Acid Phenethyl Ester; MIC, Minimal Inhibitory Concentration; MBIC, Minimal Biofilm Inhibitory Concentration; PBS, Phosphate-Buffered Saline; PI, Propidium Iodide; YPD, Yeast extract Peptone Dextrose.
\end{abstract}

\title{
References
}

1. Muñoz, J.E.; Rossi, D.C.P.; Jabes, D.L.; Barbosa, D.A.; Cunha, F.F.M.; Nunes, L.R.; Arruda, D.C.; Pelleschi Taborda, C. In Vitro and In Vivo Inhibitory Activity of Limonene against Different Isolates of Candida spp. J. Fungi 2020, 6, 183. [CrossRef]

2. Walsh, T.J.; Dixon, D.M. Spectrum of mycoses: Chapter 75. In Medical Microbiology, 4th ed.; Baron, S., Ed.; University of Texas Medical Branch at Galveston: Galveston, TX, USA, 1996.

3. Patil, S.; Rao, R.S.; Majumdar, B.; Anil, S. Clinical appearance of oral Candida infection and therapeutic strategies. Front. Microbiol. 2015, 6, 1391. [CrossRef] [PubMed]

4. Silva, S.; Henriques, M.; Martins, A.; Oliveira, R.; Williams, D.; Azeredo, J. Biofilms of non-Candida albicans Candida species: Quantification, structure and matrix composition. Sabouraudia 2009, 47, 681-689. [CrossRef]

5. Ghannoum, M.A. Candida: A causative agent of an emerging infection. J. Investig. Dermatol. Symp. Proc. 2001, 6, 188-196. [CrossRef] [PubMed]

6. Donadu, M.G.; Peralta-Ruiz, Y.; Usai, D.; Maggio, F.; Molina-Hernandez, J.B.; Rizzo, D.; Bussu, F.; Rubino, S.; Zanetti, S.; Paparella, A. Colombian Essential Oil of Ruta graveolens against Nosocomial Antifungal Resistant Candida Strains. J. Fungi 2021, 7, 383. [CrossRef]

7. Tsui, C.; Kong, E.F.; Jabra-Rizk, M.A. Pathogenesis of Candida albicans biofilm. FEMS Pathog. Dis. 2016, 74, 1-13. [CrossRef]

8. El-Houssaini, H.H.; Elnabawy, O.M.; Nasser, H.A.; Elkhatib, W.F. Correlation between antifungal resistance and virulence factors in Candida albicans recovered from vaginal specimens. Microb. Pathog. 2019, 128, 13-19. [CrossRef]

9. Soliman, S.; Alnajdy, D.; El-Keblawy, A.A.; Mosa, K.A.; Khoder, G.; Noreddin, A.M. Plants' natural products as alternative promising anti-Candida drugs. Pharmacogn. Rev. 2017, 11, 104. [CrossRef]

10. Mukherjee, P.K.; Chandra, J. Candida biofilm resistance. Drug Resist. Updatates 2004, 7, 301-309. [CrossRef] [PubMed]

11. Seneviratne, C.J.; Jin, L.; Samaranayake, L.P. Biofilm lifestyle of Candida: A mini review. Oral Dis. 2008, 14, 582-590. [CrossRef]

12. Alfarrayeh, I.I.S. Bioactivities and Potential Beneficial Properties of Propolis Ethanolic Extract, Caffeic acid phenethyl Ester, and Arabic Coffee Beans Extract. Ph.D. Thesis, University of Pécs, Pécs, Hungary, 2021.

13. Murtaza, G.; Karim, S.; Akram, M.R.; Khan, S.A.; Azhar, S.; Mumtaz, A.; Bin Asad, M.H.H. Caffeic acid phenethyl ester and therapeutic potentials. Biomed Res. Int. 2014, 2014, 145342. [CrossRef]

14. Koru, Ö.; Avcu, F.; Tanyüksel, M.; Ural, A.U.; Araz, R.E.; Şener, K. Cytotoxic effects of caffeic acid phenethyl ester (CAPE) on the human multiple myeloma cell line. Turkish J. Med. Sci. 2009, 39, 863-870. [CrossRef]

15. Huang, S.; Zhang, C.P.; Wang, K.; Li, G.Q.; Hu, F.L. Recent advances in the chemical composition of propolis. Molecules 2014, 19, 19610-19632. [CrossRef]

16. Yordanov, Y. Caffeic acid phenethyl ester (CAPE): Pharmacodynamics and potential for therapeutic application. Pharmacia 2019, 66, 107. [CrossRef] 
17. Alfarrayeh, I.; Fekete, C.; Gazdag, Z.; Papp, G. Propolis ethanolic extract has double-face in vitro effect on the planktonic growth and biofilm formation of some commercial probiotics. Saudi J. Biol. Sci. 2021, 28, 1033-1039. [CrossRef] [PubMed]

18. Cui, K.; Lu, W.; Zhu, L.; Shen, X.; Huang, J. Caffeic acid phenethyl ester (CAPE), an active component of propolis, inhibits Helicobacter pylori peptide deformylase activity. Biochem. Biophys. Res. Commun. 2013, 435, 289-294. [CrossRef]

19. Meyuhas, S.; Assali, M.; Huleihil, M.; Huleihel, M. Antimicrobial activities of caffeic acid phenethyl ester. J. Mol. Biochem. 2015, 4.

20. Mirzoeva, O.K.; Grishanin, R.N.; Calder, P.C. Antimicrobial action of propolis and some of its components: The effects on growth, membrane potential and motility of bacteria. Microbiol. Res. 1997, 152, 239-246. [CrossRef]

21. Lv, L.; Cui, H.; Ma, Z.; Liu, X.; Yang, L. Recent progresses in the pharmacological activities of caffeic acid phenethyl ester. Naunyn Schmiedebergs Arch. Pharmacol. 2021, 394, 1327-1339. [CrossRef]

22. Niu, Y.; Wang, K.; Zheng, S.; Wang, Y.; Ren, Q.; Li, H.; Ding, L.; Li, W.; Zhang, L. Antibacterial effect of caffeic acid phenethyl ester on cariogenic bacteria and Streptococcus mutans biofilms. Antimicrob. Agents Chemother. 2020, 64, e00251-20. [CrossRef] [PubMed]

23. De Barros, P.P.; Rossoni, R.D.; Garcia, M.T.; de Lima Kaminski, V.; Loures, F.V.; Fuchs, B.B.; Mylonakis, E.; Junqueira, J.C. The anti-biofilm efficacy of caffeic acid phenethyl ester (CAPE) in vitro and a murine model of oral candidiasis. Front. Cell. Infect. Microbiol. 2021, 11, 700305. [CrossRef]

24. Sun, L.; Liao, K.; Hang, C. Caffeic acid phenethyl ester synergistically enhances the antifungal activity of fluconazole against resistant Candida albicans. Phytomedicine 2018, 40, 55-58. [CrossRef]

25. Sun, L.; Hang, C.; Liao, K. Synergistic effect of caffeic acid phenethyl ester with caspofungin against Candida albicans is mediated by disrupting iron homeostasis. Food Chem. Toxicol. 2018, 116, 51-58. [CrossRef]

26. Michalak, I.; Chojnacka, K.; Witek-Krowiak, A. State of the art for the biosorption process-A review. Appl. Biochem. Biotechnol. 2013, 170, 1389-1416. [CrossRef]

27. Sutcu, M.; Salman, N.; Akturk, H.; Dalg1c, N.; Turel, O.; Kuzdan, C.; Kadayifci, E.K.; Sener, D.; Karbuz, A.; Erturan, Z. Epidemiologic and microbiologic evaluation of nosocomial infections associated with Candida spp in children: A multicenter study from Istanbul, Turkey. Am. J. Infect. Control 2016, 44, 1139-1143. [CrossRef] [PubMed]

28. Bona, E.; Cantamessa, S.; Pavan, M.; Novello, G.; Massa, N.; Rocchetti, A.; Berta, G.; Gamalero, E. Sensitivity of Candida albicans to essential oils: Are they an alternative to antifungal agents? J. Appl. Microbiol. 2016, 121, 1530-1545. [CrossRef] [PubMed]

29. Mandras, N.; Roana, J.; Scalas, D.; Del Re, S.; Cavallo, L.; Ghisetti, V.; Tullio, V. The Inhibition of Non-albicans Candida Species and Uncommon Yeast Pathogens by Selected Essential Oils and Their Major Compounds. Molecules 2021, 26, 4937. [CrossRef]

30. Possamai Rossatto, F.C.; Tharmalingam, N.; Escobar, I.E.; D'Azevedo, P.A.; Zimmer, K.R.; Mylonakis, E. Antifungal Activity of the Phenolic Compounds Ellagic Acid (EA) and Caffeic Acid Phenethyl Ester (CAPE) against Drug-Resistant Candida auris. J. Fungi 2021, 7, 763. [CrossRef] [PubMed]

31. Cigut, T.; Polak, T.; Gasperlin, L.; Raspor, P.; Jamnik, P. Antioxidative activity of propolis extract in yeast cells. J. Agric. Food Chem. 2011, 59, 11449-11455. [CrossRef]

32. Breger, J.; Fuchs, B.B.; Aperis, G.; Moy, T.I.; Ausubel, F.M.; Mylonakis, E. Antifungal chemical compounds identified using a C. elegans pathogenicity assay. PLoS Pathog. 2007, 3, e18. [CrossRef]

33. Su, Z.Z.; Lin, J.; Prewett, M.; Goldstein, N.I.; Fisher, P.B. Apoptosis mediates the selective toxicity of caffeic acid phenethyl ester (CAPE) toward oncogene-transformed rat embryo fibroblast cells. Anticancer Res. 1995, 15, 1841-1848.

34. Marin, E.H.; Paek, H.; Li, M.; Ban, Y.; Karaga, M.K.; Shashidharamurthy, R.; Wang, X. Caffeic acid phenethyl ester exerts apoptotic and oxidative stress on human multiple myeloma cells. Investig. New Drugs 2019, 37, 837-848. [CrossRef] [PubMed]

35. Sharma, A.; Srivastava, S. Anti-Candida activity of two-peptide bacteriocins, plantaricins (Pln E/F and J/K) and their mode of action. Fungal Biol. 2014, 118, 264-275. [CrossRef] [PubMed]

36. De Nollin, S.; Borgers, M. Scanning electron microscopy of Candida albicans after in vitro treatment with miconazole. Antimicrob. Agents Chemother. 1975, 7, 704-711. [CrossRef] [PubMed]

37. Lone, S.A.; Wani, M.Y.; Fru, P.; Ahmad, A. Cellular apoptosis and necrosis as therapeutic targets for novel Eugenol Tosylate congeners against Candida albicans. Sci. Rep. 2020, 10, 1-15. [CrossRef]

38. CLSI. Reference Method for Broth Dilution Antifungal Susceptibility Testing of Yeasts; Approved Standard, 2nd ed.; Clinical and Laboratory Standards Institute: Pittsburgh, PA, USA, 2002; Volume 22, ISBN 1562384694.

39. Stepanović, S.; Vuković, D.; Hola, V.; Di Bonaventura, G.; Djukić, S.; Ćirković, I.; Ruzicka, F. Quantification of biofilm in microtiter plates: Overview of testing conditions and practical recommendations for assessment of biofilm production by staphylococci. Apmis 2007, 115, 891-899. [CrossRef] [PubMed]

40. Nostro, A.; Roccaro, A.S.; Bisignano, G.; Marino, A.; Cannatelli, M.A.; Pizzimenti, F.C.; Cioni, P.L.; Procopio, F.; Blanco, A.R. Effects of oregano, carvacrol and thymol on Staphylococcus aureus and Staphylococcus epidermidis biofilms. J. Med. Microbiol. 2007, 56, 519-523. [CrossRef]

41. Sun, X.; Zhao, Y.; Liu, L.; Jia, B.; Zhao, F.; Huang, W.; Zhan, J. Copper tolerance and biosorption of Saccharomyces cerevisiae during alcoholic fermentation. PLoS ONE 2015, 10, e0128611. [CrossRef] [PubMed]

42. Yue, Q.; Zhou, X.; Leng, Q.; Zhang, L.; Cheng, B.; Zhang, X. 7-ketocholesterol-induced caspase-mediated apoptosis in Saccharomyces cerevisiae. FEMS Yeast Res. 2013, 13, 796-803. [CrossRef] [PubMed]

43. Phillips, A.J.; Sudbery, I.; Ramsdale, M. Apoptosis induced by environmental stresses and amphotericin B in Candida albicans. Proc. Natl. Acad. Sci. USA 2003, 100, 14327-14332. [CrossRef] 